\title{
MECHANISM OF CONTACT LINE MOVEMENT OF A DROPLET SPREADING OVER A SOLID SURFACE
}

\author{
Dmitry V. Feoktistov ${ }^{1, *}$, Evgeniya G. Orlova ${ }^{2}$, and Anastasia G. Islamova ${ }^{2}$ \\ ${ }^{1}$ Kutateladze Institute of Thermophysics, 630090, Novosibirsk, Russia \\ ${ }^{2}$ National Research Tomsk Polytechnic University, 634050, Tomsk, Russia
}

\begin{abstract}
The contact line movement, advancing and receding, of the distilled water droplet was studied on the polished and laser patterned aluminum surfaces. The obtained dependences of the dynamic contact angles on the contact line speed were fitted by the combined theory consisting of molecular-kinetic and hydrodynamic theories. Results obtained on laser patterned surface are found to fit better to the theory in comparison with polished surface. The assumption was made that this result is connected with the low contact angle hysteresis on the patterned surface compared to the polished one. It means that combined theory does not consider the contact angle hysteresis.
\end{abstract}

\section{Introduction}

Research [1-9] aimed at studying wetting, spreading, and phase transition of a droplet is currently very relevant. It is connected with the extensive application of the obtained results. Dynamic wetting phenomenon is widespread in the technology, for example, at droplet cooling of surfaces [10], application of various coatings [11], inkjet printing [12], oil extraction, lubrication, bonding and impregnating of various materials [13], growth of biological crystals [14]. Insufficient understanding of the three-phase contact line properties leads to deter the development of a number of technologies where rivulet flow [15], boiling [16], and droplet irrigation [17] are implemented.

A droplet placed on a solid surface spreads, tends to take an equilibrium state. The characteristics used to describe the spreading of droplets are dynamic contact angle, contact line speed and contact diameter. The most significant of these is the dynamic contact angle (DCA). There are several theories of spreading [18-20], in which DCA is mathematized as a function of the contact line speed.

In this study the possibility of applying the combined theory of spreading (as the most integrated, since it takes into account the adsorption and desorption of molecules, the forces of viscous friction in the liquid) to describe the wetting and dewetting of polished and micropatterned surfaces of aluminum substrates by liquid droplet was proved.

\footnotetext{
*Corresponding author: fdv@tpu.ru
} 
This theory assumes that the equilibrium contact angle depends on the contact line speed [18]:

$$
\theta_{D}^{3}=\left[a \cos \left(\cos \theta_{0} \pm\left(\frac{2 k_{B} T}{\sigma \lambda^{2}}\right) a \sinh \left(\frac{U}{2 k_{0} \lambda}\right)\right)\right]^{3} \pm\left(\frac{9 \mu U}{\sigma}\right) \ln \left(\frac{L}{L_{m}}\right)
$$

where $\theta_{0}$ is the equilibrium contact angle, $L$ is the characteristic capillary length, $L_{m}$ is the slip length, $k_{B}$ is the Boltzmann constant, $T$ is the temperature, $k_{0}$ is the equilibrium frequency of the random molecular displacements occurring within the threephase zone, and $\lambda$ is the average distance of each displacement.

This theory includes hydrodynamic [19] and molecular-kinetic [20] theories. From the first theory it is known that the bulk viscous friction prevents the contact line motion. The second theory supposes that the dependence of the dynamic contact angle on the contact line speed is the result of molecular adsorption and desorption on the three-phase contact line.

\section{Experimental apparatus}

Research was conducted on the experimental setup with shadow method implementation. The principle of operation is described in detailed in [21-25]. To form advancing and receding contact line, liquid was pumped in/out through an opening in the surface (Fig.1)

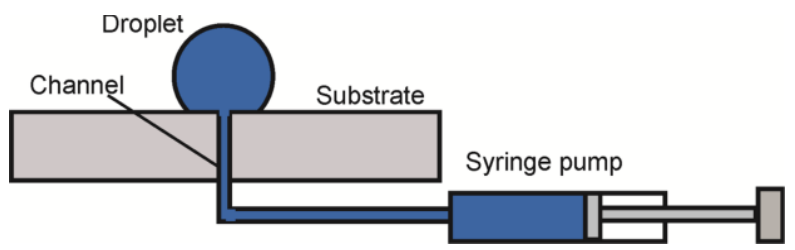

Fig. 1. Scheme of pumping in/out liquid for droplet formation.

Two substrates made of aluminum were used in the experiment. Surface of the first substrate was polished; the second was micro patterned by laser treatment. The energy in the laser pulse was $1.0 \mathrm{~mJ}$, pulsed frequency was $20 \mathrm{kHz}$, traverse speed was $500 \mathrm{~mm} / \mathrm{s}$. The surfaces were studied on the profilometer "Micro Measure 3D station" (Fig. 2). The roughness parameter was obtained for each substrate, $\mathrm{Ra}=0.0558 \mu \mathrm{m}$ and $\mathrm{Ra}=4.2096 \mu \mathrm{m}$, respectively. Microstructures are shown in Fig.2.

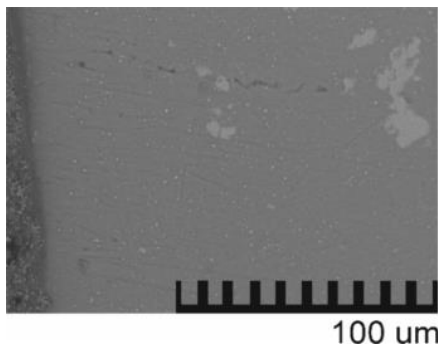

a

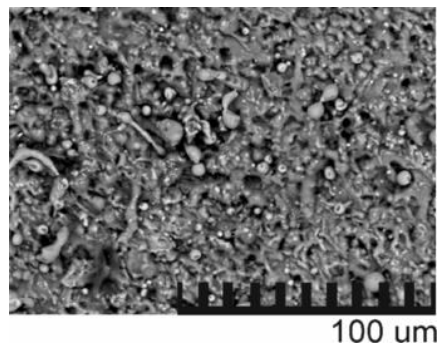

$\mathrm{b}$

Fig. 2. Surfaces of substrates $(\times 1000)$ : (a) polished; (b) patterned. 
Liquid flow rate supplied by an electronic pump was varied in the following range: 0.05 $\mathrm{mL} / \mathrm{sec}-0.11 \mathrm{~mL} / \mathrm{sec}$. The random error was calculated from the results of experiments repeated under the identical conditions. Thereafter, the mean values of the contact angle and their standard deviations were calculated. The random measurement errors were mainly due to the small deviations of flow rate during dosing the liquid through a silicone tube.

\section{Results and discussion}

The experimental data processing for the following comparison with theory [18] was performed by least squares. To evaluate fitting of the experimental data to the theory the Rsquared coefficient was obtained. Defined parameters of the combined theory for polished surface are listed in Table 1.

Parameters $k^{0}$ and $\lambda$ were obtained by approximation. The combine theory is found to describe well the experimentally obtained values of $\theta_{D}$ on polished surface. It is explained by the fact that this theory takes into account both the contact line friction and viscous forces in the bulk of liquid.

Table 1. Parameters for polished surface.

\begin{tabular}{|c|c|c|c|c|c|}
\hline \multirow{2}{*}{$\begin{array}{c}\text { Liquid flow rate, } \\
\mathrm{mL} / \mathrm{sec}\end{array}$} & Measured equilibrium & \multicolumn{5}{|c|}{ Calculated parameters } \\
\cline { 3 - 6 } contact angle $\theta_{0},{ }^{o}$ & $\theta_{0}{ }^{o}$ & $k^{0}, 10^{3} \mathrm{~Hz}$ & $\lambda, \mathrm{nm}$ & $R^{2}$ \\
\hline 0.05 & 96.5 & 91.6 & 0.47 & 3.02 & 0.758 \\
\hline 0.07 & 92.8 & 90.4 & 4.69 & 2.73 & 0.650 \\
\hline 0.09 & 85.3 & 80.5 & 0.86 & 2.98 & 0.634 \\
\hline 0.11 & 99.0 & 96.7 & 1.80 & 4.85 & 0.765 \\
\hline
\end{tabular}

Fitting of the combined theory was conducted simultaneously to the advancing and receding lines both for polished and patterned surfaces. Dependences for polished surface are presented in Fig.3.

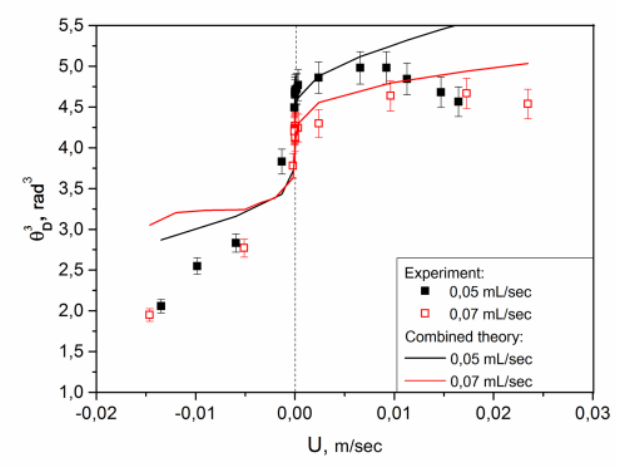

a

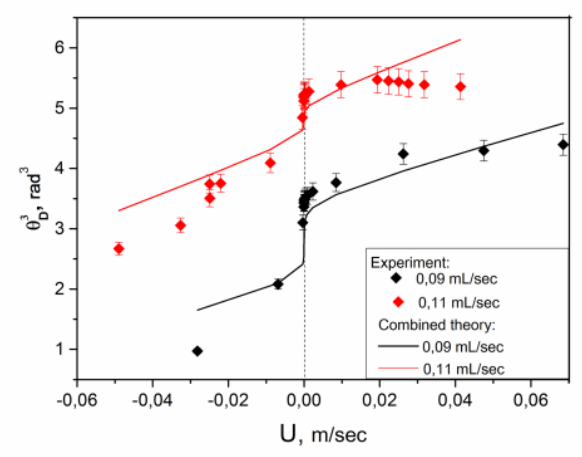

$\mathrm{b}$

Fig. 3. DCA versus contact line speed on polished surface at different values of flow rate: (a) 0.05 $\mathrm{mL} / \mathrm{sec}$ and $0.07 \mathrm{~mL} / \mathrm{sec}$; (b) $0.09 \mathrm{~mL} / \mathrm{sec}$ and $0.11 \mathrm{~mL} / \mathrm{sec}$.

Resulting parameters of the combined theory for patterned surface are listed in Table 2. Obtained dependences of the dynamic contact angle on the contact line speed are presented in Fig.4. 


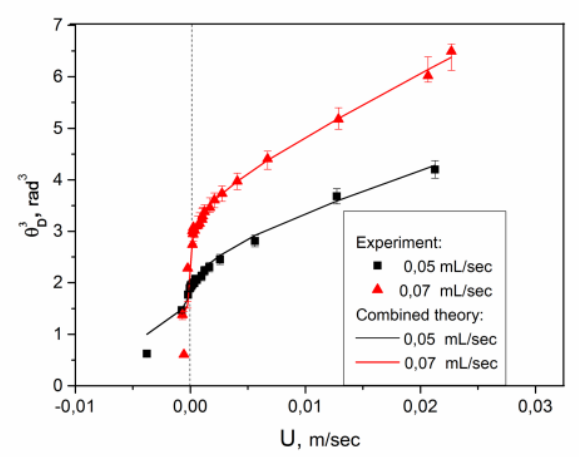

a

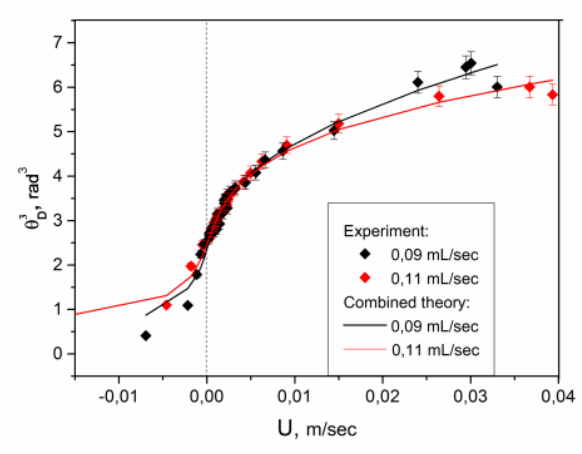

b

Fig. 4. DCA versus contact line speed on patterned surface at different values of flow rate: (a) 0.05 $\mathrm{mL} / \mathrm{sec}$ and $0.07 \mathrm{~mL} / \mathrm{sec}$; (b) $0.09 \mathrm{~mL} / \mathrm{sec}$ and $0.11 \mathrm{~mL} / \mathrm{sec}$.

Table 2. Parameters for laser patterned surface.

\begin{tabular}{|c|c|c|c|c|c|}
\hline \multirow{2}{*}{$\begin{array}{c}\text { Liquid flow rate, } \\
\mathrm{mL} / \mathrm{sec}\end{array}$} & Measured equilibrium & \multicolumn{4}{|c|}{ Calculated parameters } \\
\cline { 3 - 6 } & contact angle $\theta_{0},{ }^{\circ}$ & $\theta_{0}{ }^{o}$ & $k^{0}, 10^{3} \mathrm{~Hz}$ & $\lambda, \mathrm{nm}$ & $R^{2}$ \\
\hline 0.05 & 71.9 & 69.7 & 132.8 & 1.59 & 0.975 \\
\hline 0.07 & 80.2 & 74.2 & 4.71 & 1.75 & 0.965 \\
\hline 0.09 & 75.8 & 76.2 & 394.0 & 1.07 & 0.980 \\
\hline 0.11 & 78.9 & 77.3 & 534.3 & 1.02 & 0.989 \\
\hline
\end{tabular}

According to the results of fitting, dependences of the advancing and receding dynamic contact angle on the contact line speed obtained for patterned surface are found to fit better with the theoretical dependence compared to the results obtained on polished surface. It is connected due to the fact the dependence of combined theory (Eq. (1)) do not take into account the contact angle hysteresis. For this reason, the best fitting is observed for patterned surface with the lower hysteresis value $\left(\mathrm{H}<1.5^{\circ}\right)$ compared to the polished surface $\left(\mathrm{H}=5^{\circ}\right)$. Thus, when the liquid flow rate equaled $0.05 \mathrm{~mL} / \mathrm{sec} \mathrm{R}$-squared value for polished surface was 0.758 , for patterned -0.975 .

\section{Acknowledgements}

This work was carried out at the Kutateladze Institute of Thermo-physics SB RAS and financially supported by the Russian Science Foundation (project number 15-19-10025).

\section{References}

1. G. Kuznetsov, D. Feoktistov, E. Orlova, K. Batishcheva, Colloid J., 78, 335 (2016)

2. D. Zaitsev, E. Chinnov, O. Kabov, I. Marchuk, Tech. Phys. Lett., 30, 231 (2004)

3. V. Nakoryakov, S. Misyura, S. Elistratov, Int. J. Energy Technol., 4, 1 (2012)

4. X. Li, L. Zhang, X. Ma, H. Zhang, Surf. Coat. Technol., 307, 243 (2016)

5. Y. Lyulin, D. Feoktistov, I. Afanas'ev, E. Chachilo, O. Kabov, G. Kuznetsov, Tech. Phys. Lett., 41, 665 (2015)

6. D. Glushkov, G. Kuznetsov, P. Strizhak, Math. Probl. Eng., 2014, 920480 (2014)

7. G. Kuznetsov, A. Zakharevich, N. Bel'kov, Chem. Pet. Eng., 50, 424 (2014) 
8. V. Nakoryakov, S. Misyura, S. Elistratov, J. Eng. Thermophys., 22, 1 (2013)

9. G. Kuznetsov, D. Feoktistov, E. Orlova, Thermophysics and Aeromechanics, 23, 17 (2016)

10. D. Zaitsev, D. Rodionov, O. Kabov, Technical Physics letters, 35, 680 (2009)

11. A. Sivkov, Y. Shanenkova, A. Saigash, I. Shanenkov, Surf. Coat. Technol., 292, 63 (2016)

12. A. Oko, P. Claesson, P. Niga, A. Swerin, Nord. Pulp Pap. Res. J., 31, 156 (2016)

13. S. Basu, S. Shravan, Pet. Sci. Technol., 26, 1559 (2008)

14. A. Sivkov, A. Pak, D. Nikitin, I. Rakhmatullin, I. Shanenkov, Nanotechnol. Russ., 8, 489 (2013)

15. Y. Lyulin, O.Kabov, Tech. Phys. Lett., 39, 795 (2013)

16. V. Nakoryakov, S. Misyura, Dokl. Physics, 59, 441 (2014)

17. V. Nakoryakov, S. Misyura, S. Elistratov, Dokl. Physics, 58, 40 (2013)

18. P. Petrov, J. Petrov, Langmuir, 8, 1762 (1992)

19. O. Voinov, J. Fluid Dyn., 11, 714 (1976)

20. T. Blake, J. Haynes, J. Colloid Interface Sci., 30, 421-423 (1969)

21. E. Orlova, E. Malyhina, D. Feoktistov, L. Zhidkova, MATEC Web of Conf., 72, 01062 (2016)

22. K. Batischeva, E. Orlova, D. Feoktistov, MATEC Web of Conf., 19, 01001 (2014)

23. E. Orlova, D. Feoktistov, G. Kuznetsov, EPJ Web of Conf., 82, 01053 (2015)

24. K. Ponomarev, E. Orlova, D. Feoktistov, EPJ Web of Conf., 110, 01060 (2016)

25. E. Orlova, G. Kuznetsov, D. Feoktistov, EPJ Web of Conf., 76, 01039 (2014) 